\title{
Energy consumption in freight logistics
}

\section{Chaocheng Zheng, Xiaoying Qiu, Jiarong Mao, Lei Yu}

Nanjing Vocational Institute of Transport Technology, Nanjing, China

Keywords: Energy consumption, freight logistics, low carbon.

\begin{abstract}
Needless to say, a country's economy is boosted by circulation of logistics industry, especially China. It is obvious from the point of data 1980 to 2010 that energy consumption of China"s logistics industry are attributed to growth in logistics activity at the cost of improvement in energy intensity, thus, freight logistics should be operated in a low carbon and eco-friendly way.
\end{abstract}

\section{Introduction}

Coping with severe energy challenge has been an important research area home and abroad. Energy consumption and economic development seems as a paradox since oil crises. With significant alert on global warming, carbon emission has been focused all over the world. China is no exception at all. With the advent of the era in low-carbon economy, low-carbon concept has also quickly entered the logistics industry. Every aspect of the logistics industry will not only affect the economy and society, but resources and environment as well. On the one hand, as an important part in economic development, logistics accounts for one third of the total oil consumption. Therefore, ogistics industry is one of the key industries in China. At present, the research of low carbon logistics is still in its infancy, but the academia has begun to explore the problem of low carbon logistics. Li et al. (2011) use ANP method to establish the evaluation system of the key factors that affect the development of low carbon logistics, and noticed the government priority is 0.78 , which shows government policy has a great influence on low carbon logistics. This provides a solution to the problem of qualitative research of low carbon logistics with quantitative methods.

\section{Energy Production and Consumption}

China has been a net importer of oil since 1993. In 2010 it consumed 439 million tons standard coal and became the largest energy consumption country (Figure1). It is imperative, therefore, for the country to rethink, re-examine, and re-engineering its energy policy and those of the underlying economic activities across various industrial sectors.

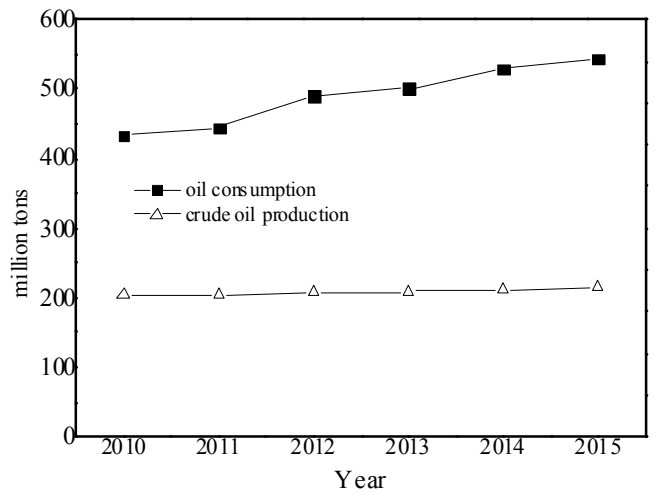

Fig. 1 Crude oil production and consumption in China from 2010 to 2015

In China, Wang et al. (2014) analyzed the current status and trend of China's transport energy consumption including road, railway, waterway and civil aviation. Chung et al. (2013) investigated the energy consumption and efficiency of China's transport sector from 2003 to 2009. Wu and Huo (2014) carried out an in-depth investigation into the effectiveness of policies in China's manufacturing and transportation sectors. Lin and Xie (2014) established the trans-log production function model for China's transport industry, which accounts for factors such as capital, energy and 
labor inputs. However, little has been done in examining energy consumption in the logistics industry which is one of the major energy-intensive industrial sectors. Only a small portion of literature has touched upon this issue.

\section{Calculation of Carbon Emissions in China's Logistics Industry}

\subsection{Calculation Method}

There are many methods to measure carbon emissions, according to the analysis of Zhang Deying et al (2005), combined with the feasibility of carbon emissions measurement in China's logistics industry, the emission coefficient method and model method are used to calculate the carbon emissions of the logistics industry. Emission coefficient method is a calculation in the normal technology, economy and management conditions, the unit production emissions statistics the average number of gas, or estimate the product energy consumption and emission coefficient based on statistical method to obtain product gas emissions. The carbon emission coefficient is the amount of carbon dioxide emitted per unit of economic output. According to IPCC, it is considered that the carbon emission coefficient of a certain energy is constant. Emission coefficient method is a list of important greenhouse gas emissions recommended by IPCC. At present, there are two kinds of discharge coefficients used in different countries: one is the pollutant discharge under the condition of recycling; the other is that there is no pollutant discharge under the condition of recovery. The basic formula is; $\mathrm{E}=\mathrm{EF} \times \mathrm{Q}$, where $\mathrm{E}$ represents the gas emissions; $\mathrm{EF}$ represents the emission coefficient while $\mathrm{Q}$ represents a product production. The other method is model method which is more suitable for the complex system affected by many factors. Therefore, the carbon emissions of the logistics industry is also estimated. The carbon emissions of the logistics industry are related to energy consumption, technical level and the level of social and economic development. In the study of the carbon emissions of macroeconomic factors, there are two kinds of models: top-down and bottom-up. The top-down model method is used to measure the consumption terminal and obtain the carbon under the conditions of certain economic input, technology use and energy supply. The bottom-up model method is used to estimate the carbon emission in different energy structure and technical application conditions through the modeling of the terminal energy optimization, technology selection and emission reduction. However, the applicability of the model method is also limited, which is more concerned with the environmental impact of the various factors in the whole ecological economic system.

\subsection{Total Logistics Energy Consumption in China}

Based on the estimation of carbon dioxide released from fossil fuel combustion put forward by ORNL lab in America, the formula of carbon dioxide emission from fossil fuel combustion could be obtained from the formula below: $\mathrm{CE}=\mathrm{En} \times \mathrm{k} \times \mathrm{n} \times 44 / 12$, where $\mathrm{CE}$ represents the carbon emissions, En represents the energy consumption, $\mathrm{K}$ represents the effective oxidation fraction, $\mathrm{n}$ represents the carbon content of the standard coal per ton.

3.2.1 The estimation formula of carbon emissions of coal burning coal: $\mathrm{CE}=$ En-coal $\times \mathrm{k} \times \mathrm{n} \times$ 44 / 12, where, En-coal represents coal consumption.

3.2.2 Formula for estimating carbon emissions from natural gas combustion is $\mathrm{CE}=$ En-gas $\times \mathrm{k}$ $\times \quad$ a $\times 44$ / 12, where En-gas represents the consumption of natural gas, while a represents the ratio of the release of carbon dioxide from coal and carbon dioxide in the case of obtaining the same heat energy.

3.2.3 Formula for estimating carbon emissions from oil burning is $\mathrm{CE}=\mathrm{En}$-oil $\times \mathrm{k} \times \beta \times 44$ / 12, where En oil represents the consumption of oil; while $\beta$ represents the ratio of the release of carbon dioxide from the oil and the release of carbon dioxide in the case of the same heat energy.

In the above formula, the effective oxidation fraction $\mathrm{K}$ value is 0.982 , the alpha value is 0.813 , the beta value is, and the $\mathrm{n}$ value is 0.68 .

As other carbon emission is rather low in logistics industry, hence, coal consumption and oil consumption are mainly used in estimating the carbon emissions of the logistics industry. According 
to these data, the vertical comparison of carbon dioxide emissions in China's logistics industry is obvious in Figure 2.

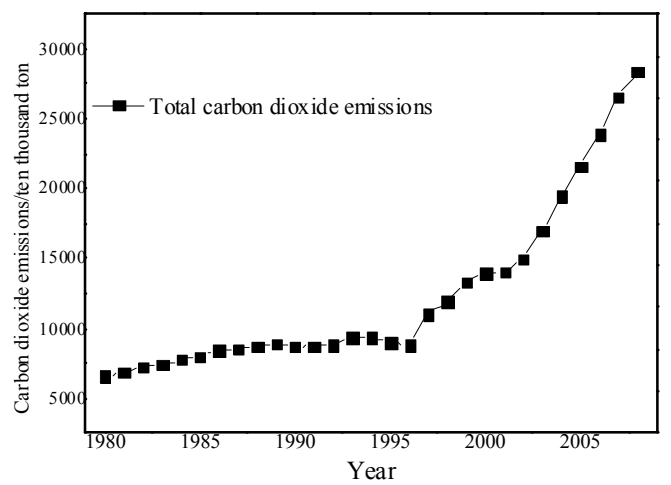

Fig. 2 Estimation of carbon dioxide emissions in China's logistics industry

The overall carbon dioxide emissions of China's logistics industry is on the rise. Before 1996, the logistics industry's carbon dioxide emissions growth is slow, while between 1996 and 2008, $\mathrm{CO}_{2}$ increased at a faster rate.

\subsection{Horizontal Comparison of Carbon Emissions between China and other Countries}

The carbon dioxide emissions of logistics industry mainly depend on the transportation department of logistics industry. Therefore, an attempt is made to estimate the carbon dioxide emissions of the road sector in various countries, so as to estimate the carbon dioxide emissions of road transportation in the logistics industry. Carbon dioxide emissions road sector, mainly refers to the amount of carbon dioxide in the road transport sector activity released by energy consumption, such as in the city roads, rural roads, highways and other activities in petroleum products, such as natural gas and electricity consumption of carbon dioxide emissions amount.

Table 1. Total carbon dioxide emissions in some countries (thousand tons)

\begin{tabular}{ccccccc}
\hline Year & China & America & Japan & India & Britain & Russia \\
\hline 2001 & 3487566.4 & 5601368.0 & 1202266.3 & 1203843.1 & 550552.4 & 1558013.0 \\
2002 & 3694242.1 & 5650957.0 & 1216751.0 & 1226791.2 & 531939.0 & 1557665.0 \\
2003 & 4525177.0 & 5681664.5 & 1237392.5 & 1281913.5 & 540640.5 & 1604972.6 \\
2004 & 5288166.0 & 5790761.4 & 1259658.5 & 1348524.6 & 540409.5 & 1602963.0 \\
2005 & 5790017.0 & 5826393.6 & 1238180.9 & 1411127.6 & 541989.9 & 1615683.9 \\
2006 & 6414463.1 & 5737615.6 & 1231297.9 & 1504364.7 & 542044.9 & 1669603.4 \\
2007 & 6791804.7 & 5828696.5 & 1251169.4 & 1611404.5 & 528631.1 & 1667575.6 \\
2008 & 7037710.1 & 5656838.9 & 1207686.1 & 1802158.2 & 522246.8 & 1715664.6 \\
2009 & 7687113.8 & 5299563.1 & 1101134.1 & 1979424.6 & 474579.5 & 1574386.1 \\
\hline
\end{tabular}

Table 2. Percentage of total fuel consumption by road sector in some countries (\%)

\begin{tabular}{ccccccc}
\hline Year & China & America & Japan & India & Britain & Russia \\
\hline 2001 & 4 & 22 & 15 & 6 & 17 & 6 \\
2002 & 4 & 22 & 15 & 6 & 18 & 6 \\
2003 & 4 & 23 & 15 & 6 & 18 & 6 \\
2004 & 4 & 23 & 15 & 6 & 18 & 6 \\
2005 & 4 & 23 & 14 & 6 & 18 & 6 \\
2006 & 4 & 23 & 14 & 6 & 18 & 6 \\
2007 & 5 & 23 & 14 & 6 & 19 & 6 \\
2008 & 6 & 23 & 14 & 7 & 19 & 7 \\
2009 & 6 & 23 & 14 & 8 & 19 & 7 \\
\hline
\end{tabular}

Table 2, shows that several of the world's carbon dioxide emissions Cij(i equals to year; $\mathrm{j}$ is on behalf of the State Road Department), road sector fuel consumption is accounted for the percentage of total consumption by a $\mathrm{ij}$, thus, carbon dioxide released in road sector by each country is followed as $\mathrm{C}_{\mathrm{ij}}$ plus $\alpha_{\mathrm{ij}}$, as indicated in Table 3. 
Table 3. Total fuel consumption in road sector in some countries (\%)

\begin{tabular}{ccccccc}
\hline Year & China & America & Japan & India & Britain & Russia \\
\hline 2001 & 13950.27 & 123230.10 & 18033.99 & 7223.06 & 9359.39 & 9348.03 \\
2002 & 14776.97 & 124321.10 & 18251.27 & 7360.75 & 9574.90 & 9345.99 \\
2003 & 18100.71 & 130678.30 & 18560.8 & 7691.48 & 9731.53 & 9629.84 \\
2004 & 21152.66 & 133187.50 & 18894.88 & 8091.15 & 9727.37 & 9617.78 \\
2005 & 23160.07 & 134007.10 & 17334.53 & 8466.77 & 9755.82 & 9694.10 \\
2006 & 25657.85 & 131965.20 & 17238.17 & 9026.19 & 9756.81 & 10017.62 \\
2007 & 33959.02 & 134060.00 & 17516.37 & 9668.43 & 10043.99 & 10005.45 \\
2008 & 42226.26 & 130107.30 & 16907.61 & 12615.11 & 9922.69 & 12009.65 \\
2009 & 46122.68 & 121890.00 & 15415.88 & 13855.97 & 9017.01 & 11020.70 \\
\hline
\end{tabular}

From the horizontal angle of view, has been the highest in the United States road transport logistics industry carbon dioxide emissions; since 2003, the logistics industry of our country road transport carbon dioxide emissions exceeded Japan become the listed amount of high national emission in several countries in the logistics industry. From the vertical perspective, carbon dioxide emissions of the logistics industry in America, Japan, road transportation volume of India, Britain, Russia, with the passage of time has little change, in a relatively stable state; the logistics industry of our country road transport carbon emissions showed a clear upward trend. $2002 \sim 2007$ years, China's logistics industry road transport carbon dioxide emissions increased at a faster rate, during the catch up with Japan and a higher number of higher than japan. It can be seen that China's logistics industry road transport carbon dioxide emissions is not only a high number of emissions, and the growth rate.

\section{Summary}

From 1980 to 2008 carbon emissions of logistics enterprises, the logistics industry carbon emissions in China increased, and in 1996 to 2008 years, the carbon emissions increase speed; seen from China and 2001 major countries in the world carbon dioxide emissions in 2009 logistics transportation relations, carbon emissions the logistics industry of our country not only higher emissions, but also in the rapid growth trend. It can be seen that the development of China's logistics industry is in the stage of high carbon logistics, that is, the development of China's logistics industry is based on the development of high carbon logistics. Based on the overall situation of China's carbon emission reduction, it is necessary to complete the transition from high carbon to low-carbon logistics as soon as possible. According to the experience of developed countries, it is necessary for the government, enterprises and the public to participate, and the government mechanism, market mechanism and social mechanism

\section{Acknowledgments}

This work was financially supported by a grant from Project of Philosophy and Social Science Research in Colleges and Universities in Jiangsu Province (2016SJD630040), college student' s innovation and entrepreneurship training programme in Jiangsu province (201612804015Y), and High-level Scientific Research Foundation for the introduction of talent in Nanjing Vocational Institute of Transport Technology.

\section{References}

[1]. Abdallah, K.B., Belloumi, M., De Wolf, D., 2013. Indicators for sustainable energy development: a multivariate cointegration and causality analysis from Tunisian road transport sector. Renew. Sustain. Energy Rev. 25, 34 - 43.

[2]. Mraihi, R., ben Abdallah, K., Abid, M., 2013. Road transport-related energy consumption: analysis of driving factors in Tunisia. Energy Policy 62, $247-253$. 
[3]. Reddy, B.S., Ray, B.K., 2010. Decomposition of energy consumption and energy intensity in Indian manufacturing industries. Energy Sustain. Dev. 14 (1), 35 - 47.

[4]. Tang, S., Wang, W., Yan, H., Hao, G., 2014. Low carbon logistics: reducing shipment frequency to cut carbon emissions. Int. J. Prod. Econ. 164, 339 - 350. 